libraries of teaching hospitals and will be sought for by aspiring young genito-urinary surgeons.

I. M. B.

TREATMENT BY MANIPULATION.-BY A. G TImbrell Fisher, M.C., M.B., Ch.B., F.R.C.S: (Eng.). Fifth Edition. 1948. H. K. Lewis and Company, LImited, London. Pp. Ix plus 275 with 126 illustrations. Price, 25s.

A READABLE exposition of manipulation methods in the treatment of disabilities following injuries and some diseases. A discussion with arguments in favour of manipulative procedure in the conflict between rest and movement is well expressed and illustrative cases help towards the manipulation methods. The manipulations are fully and lucidly described in almost every case needing such procedure and those interested in the prevention and treatment of disabilities following injury and disease will find the book useful.

\section{M. B.}

\section{THE TREATMENT OF MALIGNANT DISEASE BY RADIUM AND X-RAYS BEING A PRACTICE OF RADIOTHERAPY.-By Ralston Paterson, M.C., M.D., F.R.C.S.E., D.M.R.E., F.F.R. 1948. Edward Arnold and Company, London. Pp. 612 exclusive of Index and Dosage Graphs. Profusely illus- trated. Price, 45s.}

Is his introduction the author states this book is essentially a statement of the principles and practice of the Radium Institute in Manchester (now part of the Christic Cancer Hospital and Holt Radium Institute) and there is no intention of implying that the methods and ideas presented are necessarily the best, the correct or the only methods.

In keeping with this concept the first three chapters of the book are concerned with the particular principles on which the Manchester system is based.

$\mathrm{He}$ further states that it is impossible to make any justifiable distinction between $x$-ray therapy and radium therapy. The two are essentially the same in principle and effect, differing only in those factors which result from the different origin of the two radiations and which therefore govern their applicability.

Finally put succinctly, the book starts with, as its medium gamma rays after they have left the needles or tubes, and $x$-rays as a beam of radiation on the patient's side of the filter.

And now for the book.

From what has been said above it will be gathered that the book gives an overall account of the treatment of malignant disease by radium and $x$-rays from the Manchester viewpoint.

After dealing with general principles, there is an interesting section devoted to beam directed field $x$-ray therapy, with a description of various gadgets including the back pointer and entrance directors. This is a comparatively new development which is further developed in subsequent chapters.

The radium dosage system is described in another chapter. The Manchester system was first introduced to the medical profession in papers by Paterson, Parker and others in 1934 and 1938, and has proved of immense value to workers in the radium treatment of malignant disease. In this connection a number of radium dosage graphs are inserted after the index. These give the number of $\mathrm{mg}$. hours required to give $1000 \mathrm{r}$ under different conditions.

As regards the treatment of malignant disease of different parts of the body, the whole field is adequately covered.

There are sections on Teleradium Therapy and new Radiotherapeutic agents.

Although limited in its general outlook to the Manchester point of view, this book is an admirable production; for apart from suggesting a line of advance through hostile territory, it is replete with a description of the ways and means.

It can be cordially recommended as a mine of information on all aspects of the subject and as well as for the clarity and conciseness of its presentation.
The publishers are to be congratulated on the reproductions of illustrations and the general get-up of the book.

\section{J. A. S.}

\section{MINOR SURGERY. FOR THE USE OF HOUSE} SURGEONS, DRESSERS AND JUNIOR PRACTITIONERS.-By C. Fleming, O.B.E., M.Ch., F.R.C.8. With a chapter on 'The Administration of Anæsthetics'. By H. N. Webber, B.Ch., D.A. Twentythird Edition. 1946. J. and A. ChurchllI LImIted, London. Pp. vili plus 406. Illustrated. Price, 148.

$A_{N}$ old friend appears again in a new edition. That it has passed through 26 editions with an average period of $3 \frac{1}{2}$ years between each of them shows how the book has been appreciated. Well-known men have thought it worth while to revise and bring out new editions. To older men the book is so familiar that one likes to keep a new edition as soon as it appears. The book is recommended to all students and house surgeons in our country as they will always find ready help in almost every instance when it is needed.

\section{M. B.}

FEAR.-By M. P. Leahy, M.B., B.Ch., B.A.O. (Dub.). 1948. Research Books Limited, London. Pp. xvll plus 165. Price, 10s. 6d.

After losing a limb in the First World War Dr. Leahy was overcome by depression and fear. He acquired the technique of overpowering both.

In this little book he gives numerous case reports. In all of them he was successful in dissipating fear. Obviously Dr. Leahy possesses an extraordinary power of persuasion and suggestion without being aware of it.

The book is well worth reading.

D: $\mathrm{G}$.

REPRODUCTION AND SURVIVAL.-By R. Christlo Brown, M.B., M.S., F.R.C.S., F.R.C.O.G. 1948 Edward Arnold and Company, London. Pp. 108. Price, 6s.

$\mathrm{IN}_{\mathrm{N}}$ this little book Dr. R. Christie Brown talks as a biologist to biologically inclined readers.

"Nature is so careful of the type, so careless of the single life.'

Reproduction is truly a marvel and with it are linked the twin sciences of eugenics and-dysgenics.

The range of the topics is vast in spite of the small size of the book.

The reader wonders it women and men made sterile by their anatomy and physiology should be helped over the fence by medical science in A.I.H.? A perfectly legal and ethical operation might propagate sperms which ought to have perished because they failed to pass the 'interface' with their own activity.

Certain ancient peoples keen on eugenics exposed their naturally conceived and born offspring because the size and weight did not conform to standard. A.I.H. appears to be doing the opposite in the light of the information given by the author. This is a single example. The reader will find-others.

A book well worth reading.

D. G.

\section{BOOKS RECEIVED}

1. Kemsol. Journal of the King Edward Medical School, Indore (with Mahatma Gandhi Supplement). Volume III, Number 1, June 1948. Edited and published by Dr. P. S. Vasavada, M.D., Editor-in-Chief for the Kemsol. Editorial Board, K.E.H., Medical School, Indore.

2. The Nation's Health : A Ten-Year Programme A Report to the President by Oscar R. Ewing, Federal Security Administrator. For sale by the Superintendent of Documents, U,S. Government Printing - Office, Washington. 25, D.C. Price, $\$ 1.00$. 